\title{
Valorização catalítica de biomassa lenhocelulósica por hidrogenação hidrolítica em produtos de valor acrescentado
}

\author{
Lucília Graciosa de Sousa Ribeiro \\ Laboratório de Processos de Separação e Reação - Laboratório de Catálise e Materiais (LSRE-LCM), \\ Faculdade de Engenharia da Universidade do Porto, Porto, Portugal
}

\begin{abstract}
Catalytic valorization of lignocellulosic biomass to high added-value products by hydrolytic hydrogenation - The selective conversion of biomass is of extreme industrial importance in order to contribute to the replacement of fossil fuels and to the sustainable production of compounds with high added value. On the other hand, the conversion of cellulose is extremely difficult due to its strongly crystalline structure. In this work, cellulose ball-milling has shown to be an efficient and sustainable pretreatment method (unlike the usual use of acids) capable of considerably reducing its degree of crystallinity and, consequently, facilitating its conversion. Catalysts were then efficiently synthesized for the direct conversion of cellulose and hemicelluloses (xylan) into sorbitol and xylitol in yields close to $80 \%$ by hydrolytic hydrogenation. These results are among the best ever obtained for the catalytic conversion of cellulose and xylan by an environmentally friendly process for the production of those compounds of high practical interest. In addition, considerable sorbitol yields (50\%) were also obtained from the direct conversion of cellulosic materials that are generally considered as waste (e.g. cotton and paper).
\end{abstract}

\begin{abstract}
A conversão seletiva da biomassa é de extrema importância industrial no sentido de contribuir para a substituição dos combustíveis fósseis e para a produção sustentável de compostos com elevado valor acrescentado. Por outro lado, a conversão da celulose é extremamente difícil devido à sua estrutura fortemente cristalina. Neste trabalho, a moagem da celulose revelou ser um método de pré-tratamento eficiente e sustentável (em oposição à utilização habitual de ácidos) capaz de diminuir consideravelmente o seu grau de cristalinidade e, por consequência, facilitar a sua conversão. Foram sintetizados eficientemente catalisadores para a conversão direta de celulose e hemiceluloses (xilana) por hidrogenação hidrolítica, tendo-se obtido rendimentos de sorbitol e de xilitol próximos de $80 \%$. Estes resultados encontram-se entre os melhores alguma vez obtidos para a conversão catalítica de celulose e de xilana por um processo amigo do ambiente para a produção daqueles compostos de elevado interesse prático. Além disso, obtiveram-se ainda rendimentos consideráveis de sorbitol (50\%) a partir da conversão direta de materiais celulósicos geralmente considerados como resíduos (e.g. algodão e papel).
\end{abstract}

\section{Desenvolvimento sustentável}

As fontes energéticas detêm, desde a antiguidade, um papel fundamental no desenvolvimento social e económico da humanidade. Estes recursos proporcionam conforto pessoal, mobilidade e riqueza, a nível industrial e comercial. Contudo, ao longo do último século, o constante crescimento da população e a industrialização têm vindo a aumentar consideravelmente o consumo de energia [1]. Além disso, a queima dos combustíveis fósseis e dos seus derivados para a produção de calor e energia está associada ao aumento do nível de gases com efeito de estufa [1]. Num contexto de crescimento económico cada vez mais forte, a necessidade de reduzir a dependência dos combustíveis fósseis é preenchida recorrendo à racionalização dos recursos, ao aumento da eficiência dos dispositivos clássicos de conversão de energia e pelo investimento nas energias renováveis que, além de contribuírem para diminuir a necessidade de importação de recursos, permitem alcançar o desenvolvimento energético sustentável. É por este motivo que a exploração de fontes de energia renovável se torna cada vez mais importante, não só devido à consciencialização crescente para as alterações climáticas como também à escassez das matérias-primas fósseis tradicionalmente utilizadas na produção de eletricidade (petróleo, gás natural e carvão) [2].

As principais fontes renováveis, pressupondo o desenvolvimento sustentável do setor energético, são a biomas- sa, a energia solar e a energia eólica. No entanto, há que dar ênfase a duas particularidades da biomassa: a multiplicidade de matérias com potencial energético, entre as quais se destacam os resíduos agrícolas, florestais e industriais, e o seu processo de conversão. Além das óbvias vantagens no setor energético, a utilização da biomassa apresenta ainda benefícios a nível social e florestal. Em relação ao primeiro aspeto, destaca-se a neutralidade em termos de emissões de dióxido de carbono, bem como o desenvolvimento regional e local. A nível florestal, a utilização de resíduos florestais como fonte energética apresenta-se como um fator que minimiza o risco de incêndio e a sua gravidade.

\section{Biomassa lenhocelulósica como recurso renovável}

A biomassa lenhocelulósica é uma das fontes de energia renovável mais importantes, sendo um dos recursos energéticos mais antigos que a humanidade conhece. Ela inclui uma grande variedade de fontes como: resíduos florestais (serradura, resíduos da indústria de papel), parte dos resíduos sólidos urbanos, resíduos agrícolas (palhas, caules) e culturas energéticas [3].

A biomassa lenhocelulósica é habitualmente constituída por celulose (38-50\%), hemiceluloses (23-32\%) e lenhina (15-25\%) (Figura 1) [4]. Sendo a celulose a fonte de matéria-prima renovável mais abundante no planeta, é especialmente importante investigar as suas possibilidades 
de transformação, já que constitui uma das alternativas mais atrativas para a substituição das matérias-primas fósseis para a produção de produtos de valor acrescentado e de combustíveis $[4,5]$.

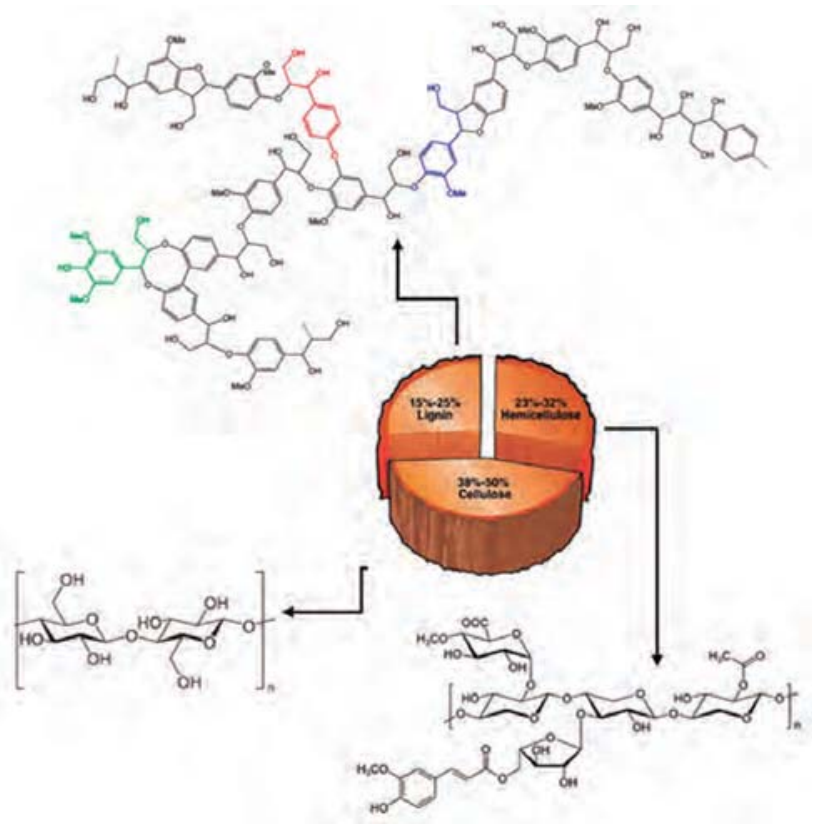

Figura 1 - Constituição da biomassa lenhocelulósica.

Diversos processos têm vindo a ser desenvolvidos para a conversão de biomassa lenhocelulósica [4,6]. A hidrogenação hidrolítica da celulose na presença de um catalisador heterogéneo apropriado é um dos mais atrativos [7-10]. Esse método consiste na hidrólise da celulose em glucose, combinada com a subsequente hidrogenação desta em compostos de interesse, como o sorbitol (Figura 2) [11-13]. Este é um composto muito importante e com inúmeras aplicações nas indústrias farmacêutica e alimentar [14], encontrando-se no TOP-12 dos produtos de elevado valor acrescentado que podem ser obtidos a partir da biomassa [15].

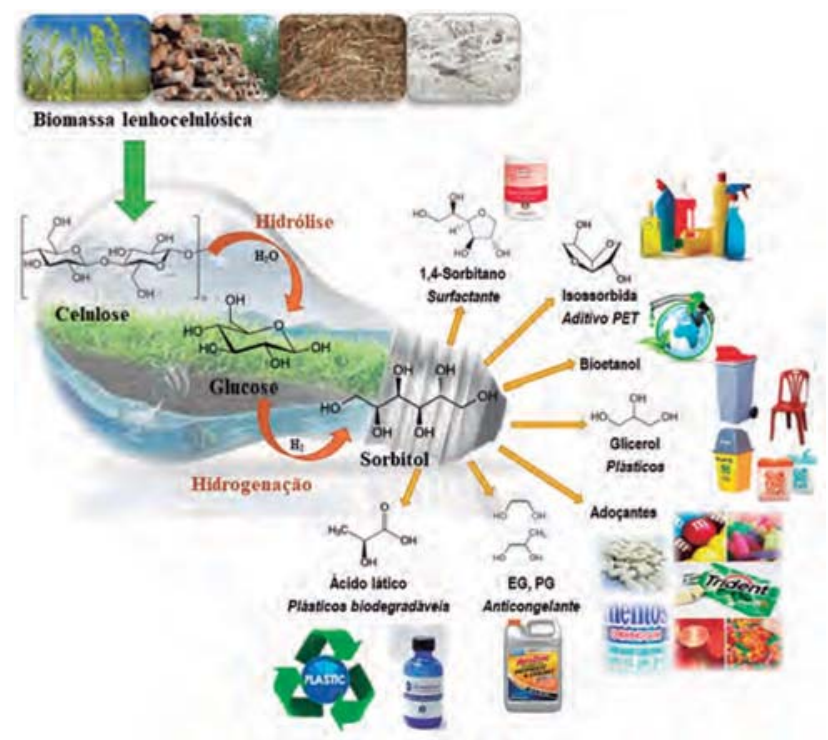

Figura 2 - Esquema ilustrativo da hidrogenação hidrolítica da celulose em sorbitol e algumas das suas possíveis aplicações.
Considerando os passos individuais da conversão da celulose, geralmente são usados catalisadores ácidos em fase líquida para a hidrólise e catalisadores metálicos para a hidrogenação. Contudo, este processo não é sustentável e traz problemas de corrosão e de recuperação/eliminação dos ácidos [16]. Assim, os catalisadores heterogéneos são preferíveis, tanto pela facilidade de separação como pela possibilidade de reutilização e capacidade de suportar condições reacionais diversas [17-19]. Desta forma, a hidrogenação hidrolítica da biomassa lenhocelulósica apresenta-se como uma alternativa promissora pela sua eficiência energética e sustentabilidade comparativamente com outros processos de conversão.

\section{Pré-tratamento da biomassa}

A celulose presente na biomassa lenhocelulósica é extremamente resistente à hidrólise. Portanto, a biomassa tem de ser submetida a um pré-tratamento a fim de facilitar a conversão da celulose em açúcares. Têm sido desenvolvidos diversos métodos de pré-tratamento com o propósito de quebrar a estrutura lenhocelulósica (Figura 3), nomeadamente a trituração e moagem, o uso de líquidos iónicos, agentes oxidantes, solventes orgânicos, etc. $[20,21]$.

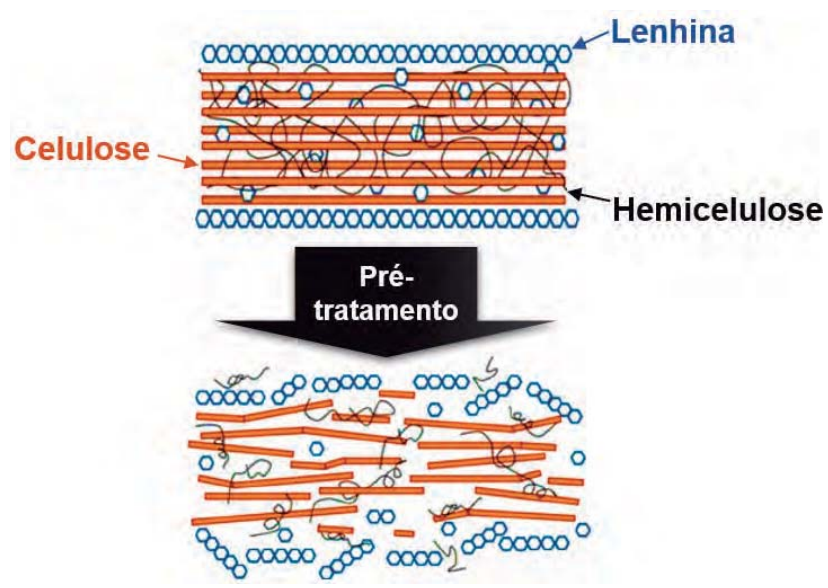

Figura 3 - Representação esquemática do pré-tratamento da biomassa.

Uma vez que a estrutura cristalina da celulose limita o seu contacto com os catalisadores, têm sido usados tratamentos mecânicos [6] pois são métodos amigos do ambiente e geralmente são bastante eficazes para melhorar a reatividade da celulose e/ou lenhocelulose devido à redução do tamanho de partículas, ao aumento da área superficial total, e à destruição da estrutura cristalina [22]. Assim, a moagem, nomeadamente em moinhos de bolas [23-25], é geralmente utilizada para quebrar a estrutura cristalina [26]. Neste trabalho [27], a moagem provocou um decréscimo do grau de cristalinidade da celulose, o que originou uma melhoria tanto da conversão como da produção de sorbitol (Figura 4). Num teste adicional moeu-se a celulose juntamente com o catalisador ( $m i x$ -milling), o que resultou num aumento significativo da velocidade de reação, acompanhado de um aumento da seletividade em sorbitol. 


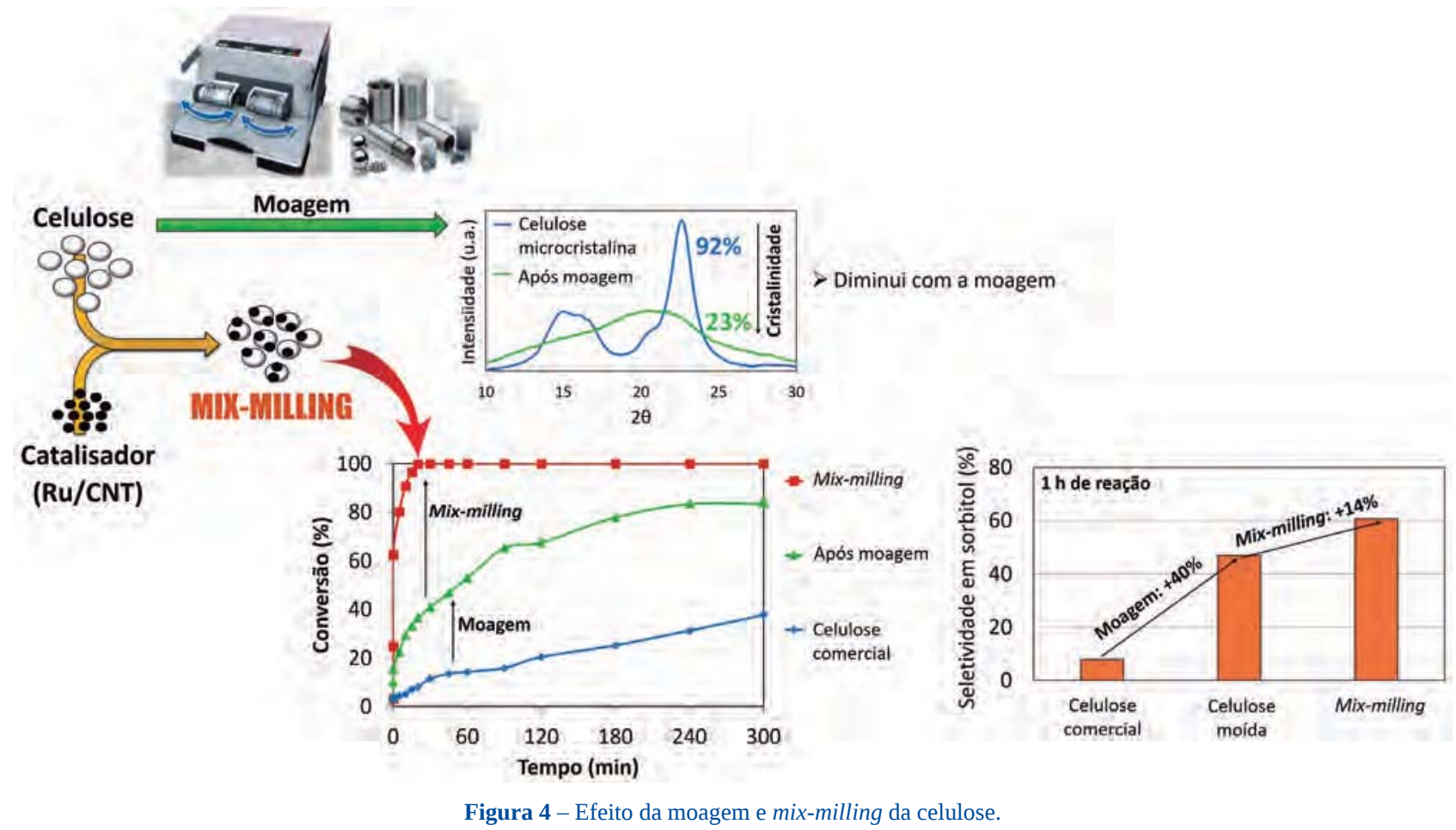

\section{Conversão catalítica da biomassa lenhocelulósica}

Um dos caminhos mais promissores para a utilização da biomassa lenhocelulósica é a sua conversão em compostos de elevado valor (ex.: sorbitol, xilitol). Normalmente este processo envolve um passo inicial de hidrólise (para transformar a celulose ou as hemiceluloses nos açúcares correspondentes) seguido de uma hidrogenação para converter os açúcares nos compostos de interesse (Figura 5) [11-13]. De forma a diminuir o tempo de reação, reduzir os resíduos formados e o consumo de matérias-primas (energia e solventes), é essencial efetuar a conversão da biomassa num único passo, com a hidrólise e a hidrogenação a ocorrer simultaneamente (Figura 5) [28]. A utilização de catalisadores multifuncionais que contêm centros ácidos (para a hidrólise) e metálicos (para a hidrogenação) é uma via atrativa para a transformação da biomassa em produtos químicos de elevado valor acrescentado [29]. Portanto, um bom equilíbrio entre as duas funções catalíticas do catalisador é fundamental.

Neste trabalho foram inicialmente otimizadas as diferentes condições reacionais para a conversão da celulose, nomeadamente a pressão de $\mathrm{H}_{2}$, a temperatura de reação, a razão $\mathrm{H}_{2} \mathrm{O}$ /substrato, a velocidade de agitação, a quantidade de catalisador e a natureza e o teor da fase metálica [30]. Prepararam-se diferentes catalisadores metálicos (Ru, Pt, $\mathrm{Pd}$, Ir, Rh) suportados em diferentes materiais, nomeadamente carvão ativado (AC), nanotubos de carbono (CNT),



Figura 5 - Conversão catalítica direta da celulose e das hemiceluloses (xilana). 
xerogéis de carbono, grafeno, grafite, negro de carbono, zeólitos e alumina [31]. O catalisador Ru/CNT foi o mais ativo e seletivo para a conversão direta de celulose em sorbitol [31,32]. Posteriormente, prepararam-se catalisadores bimetálicos de $\mathrm{Ru}-\mathrm{Ni}$ e verificou-se um efeito promotor pela adição de $\mathrm{Ni}$, associado a um aumento tanto da conversão como do rendimento de sorbitol (Figura 6) [33]. O mix-milling da celulose com os catalisadores bimetálicos permitiu ainda obter um rendimento de sorbitol entre 71$74 \%$ após apenas uma hora (Figura 6). Além disso, os catalisadores apresentaram excelente estabilidade após várias utilizações, mesmo com mix-milling.

À semelhança do estudo realizado para a celulose, desenvolveu-se um sistema para a conversão direta de xilana em xilitol [34], e testou-se ainda o efeito da presença de celulose na conversão da xilana [35]. A conversão simultânea dos dois substratos permitiu aumentar o rendimento de xilitol e de sorbitol comparativamente com o obtido na conversão separada de cada um dos substratos nas mesmas condições (Figura 7) [36]. Mais uma vez o catalisador mostrou-se extremamente estável após o uso repetido.

Por último, foi também considerada a valorização de materiais celulósicos que, após a sua utilização, são normalmente encarados como resíduos, nomeadamente algodão, tecido de algodão e lenços de papel [37]. Estes materiais foram direta e eficientemente convertidos em sorbitol com rendimentos próximos de $50 \%$ ao fim de duas horas.

\section{Conclusões}

A metodologia usada é inovadora e permite reduzir custos, maximizar a produtividade e minimizar os resíduos gerados e o consumo de energia. Obteve-se sorbitol e xilitol com elevados rendimentos diretamente da celulose, da xilana e de resíduos celulósicos.

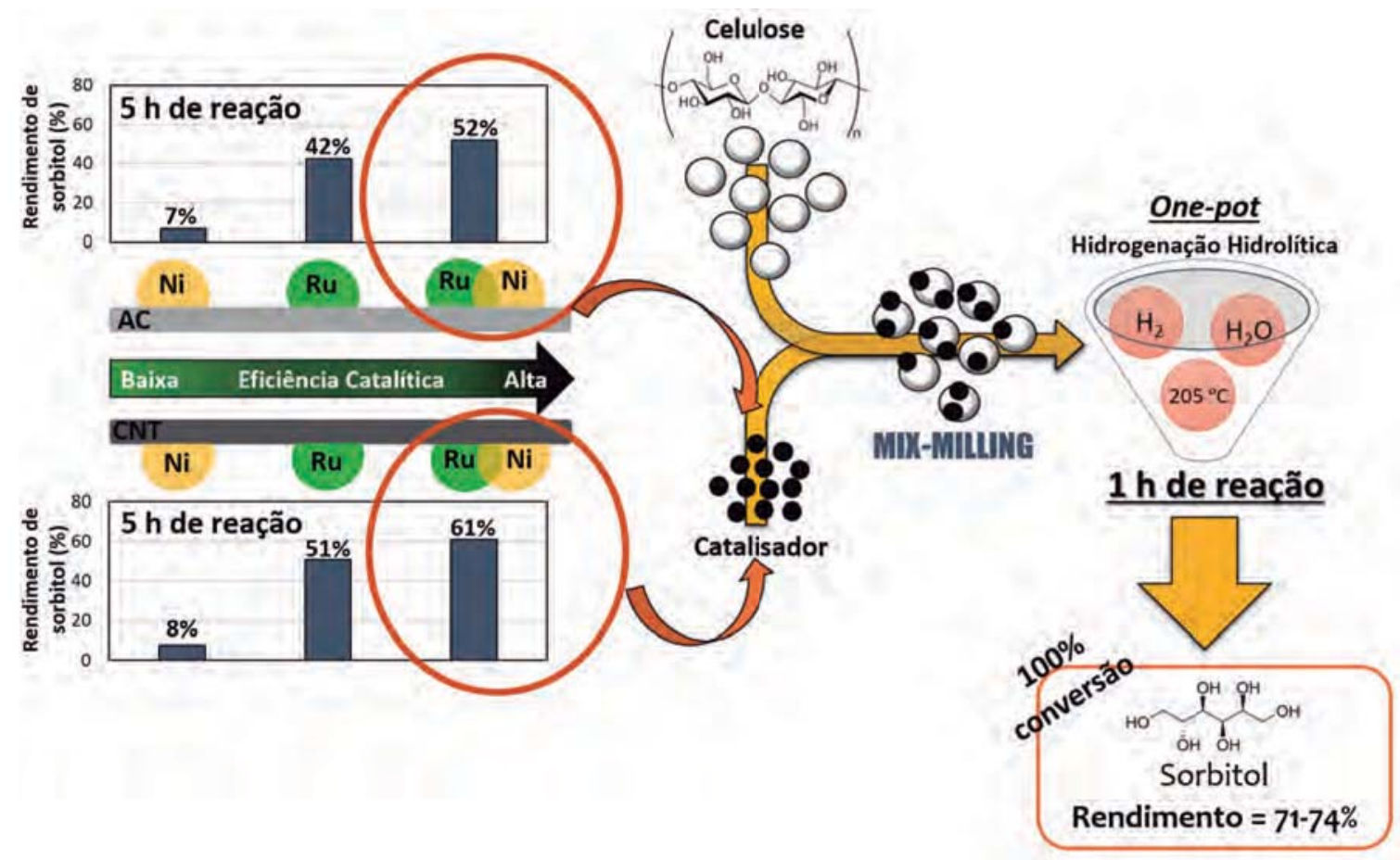

Figura 6 - Efeito do Ni e do mix-milling no rendimento de sorbitol.

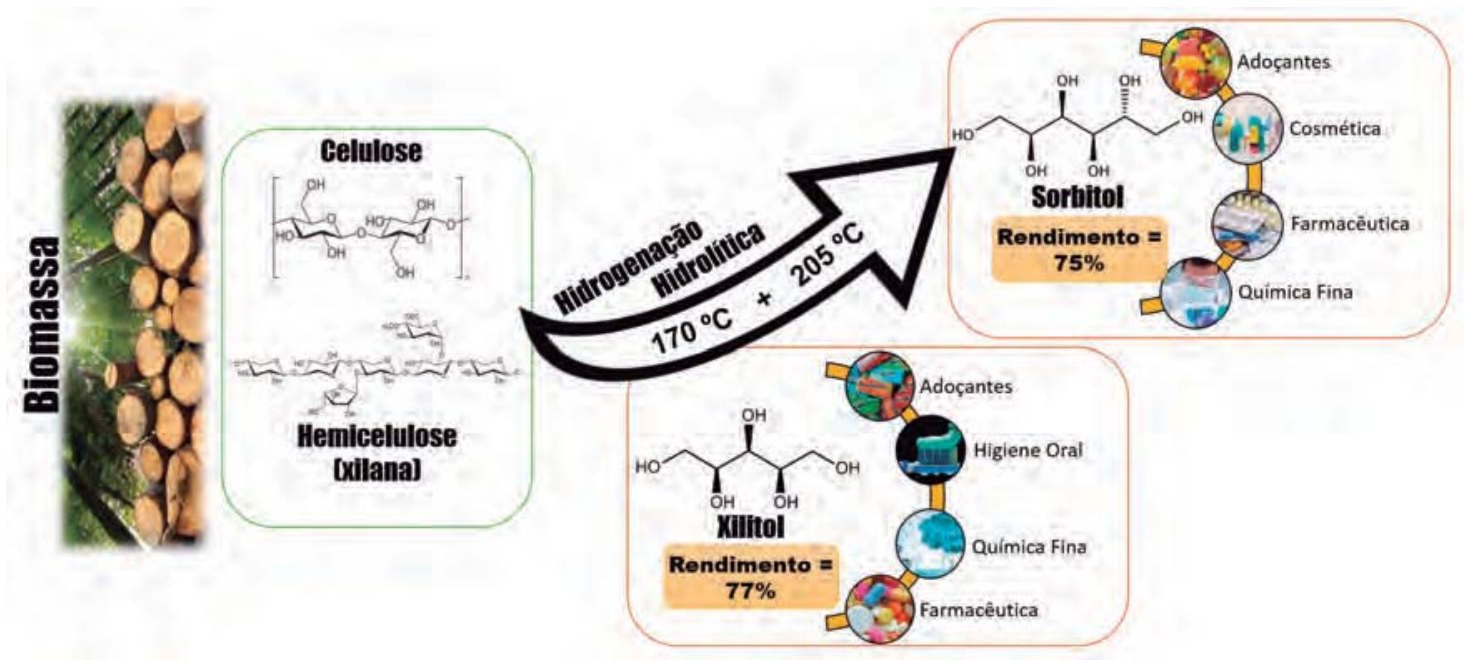

Figura 7 - Conversão simultânea da celulose e da xilana. 


\section{Agradecimentos}

Este trabalho foi desenvolvido no âmbito do projeto “AIProcMat@N2020 - Advanced Industrial Processes and Materials for a Sustainable Northern Region of Portugal 2020”, com referência NORTE-01-0145-FEDER-000006, cofinanciado pelo Programa Operacional Regional do Norte (NORTE 2020), através do Portugal 2020 e do Fundo Europeu de Desenvolvimento Regional (FEDER) e do Projeto POCI-01-0145-FEDER-006984 - Laboratório Associado LSRE-LCM - financiado pelo FEDER, através do COMPETE2020 - Programa Operacional Competitividade e Internacionalização (POCI) e por fundos nacionais através da Fundação para a Ciência e a Tecnologia (FCT). L.S. Ribeiro agradece aos orientadores Dr. Manuel Fernando Ribeiro Pereira e Dr. José Joaquim de Melo Órfão, e à FCT pela bolsa de doutoramento SFRH/BD/86580/2012.

\section{Referências}

[1] J.N. Chheda, G.W. Huber, J.A. Dumesic, Angew. Chem. Int. Ed. 46 (2007) 7164-7183.

[2] J. Zhang, J. Zhuang, L. Lin, S. Liu, Z. Zhang, Biomass Bioenerg. 39 (2012) 73-77.

[3] G.H. Jeong, E.G. Kim, S.B. Kim, E.D. Park, S.W. Kim, Micropor. Mesopor. Mat. 144 (2011) 134-139.

[4] C.-H. Zhou, X. Xia, C.-X. Lin, D.-S. Tong, J. Beltramini, Chem. Soc. Rev. 40 (2011) 5588-5617.

[5] G.W. Huber, A. Corma, Angew. Chem. Int. Ed. 46 (2007) 7184-7201.

[6] A. Cabiac, E. Guillon, F. Chambon, C. Pinel, F. Rataboul, N. Essayem, Appl. Catal. A-Gen. 402 (2011) 1-10.

[7] L. Yang, X. Yan, Q. Wang, Q. Wang, H. Xia, Carbohyd. Res. 404 (2015) 87-92.

[8] A. Negoi, K. Triantafyllidis, V.I. Parvulescu, S.M. Coman, Catal .Today 223 (2014) 122-128.

[9] H. Kobayashi, Y. Hosaka, K. Hara, B. Feng, Y. Hirosaki, A. Fukuoka, Green Chem. 16 (2014) 637-644.

[10] J. Geboers, S. Van De Vyver, K. Carpentier, P. Jacobs, B. Sels, Chem. Commun. 47 (2011) 5590-5592.

[11] A. Fukuoka, P. Dhepe, Angew. Chem. Int. Ed. 45 (2006) 5161-5163.

[12] C. Luo, S. Wang, H. Liu, Angew. Chem. Int. Ed. 46 (2007) 7636-7639.

[13] W. Deng, X. Tan, W. Fang, Q. Zhang, Y. Wang, Catal .Lett. 133 (2009) 167-174.

[14] A.M. Ruppert, K. Weinberg, R. Palkovits, Angew. Chem. Int. Ed. 51 (2012) 2564-2601.

[15] T. Werpy, G. Petersen, Top Value-Added Chemicals from Biomass. Volume 1: Results of Screening for Potential Can- didates from Sugars and Synthesis Gas. (U.S. Department of Energy, Energy Efficiency and Renewable Energy, Battelle), 2004.

[16] H. Wang, L. Zhu, S. Peng, F. Peng, H. Yu, J. Yang, Renew. Energ. 37 (2012) 192-196.

[17] R. Rinaldi, F. Schuth, Energ. Environ. Sci. 2 (2009) 610626.

[18] S. Van de Vyver, J. Geboers, P.A. Jacobs, B.F. Sels, ChemCatChem 3 (2011) 82-94.

[19] M.J. Climent, A. Corma, S. Iborra, Chem. Ver. 111 (2010) 1072-1133.

[20] P. Kumar, D.M. Barrett, M.J. Delwiche, P. Stroeve, Ind. Eng. Chem. Res. 48 (2009) 3713-3729.

[21] G. Brodeur, E. Yau, K. Badal, J. Collier, K.B. Ramachandran, S. Ramakrishnan, Enzyme Res. 2011 (2011) 1-17.

[22] N.V. Gromov, O.P. Taran, K.N. Sorokina, T.I. Mishchenko, S. Uthandi, V.N. Parmon, Catal. Ind. 8 (2016) 176-186.

[23] P. Dhepe, A. Fukuoka, ChemSusChem 1 (2008) 969-975.

[24] T. Komanoya, H. Kobayashi, K. Hara, W.-J. Chun, A. Fukuoka, Appl. Catal. A-Gen. 407 (2011) 188-194.

[25] J. Pang, M. Zheng, A. Wang, T. Zhang, Ind. Eng. Chem. Res. 50 (2011) 6601-6608.

[26] M. Yabushita, H. Kobayashi, A. Fukuoka, Appl. Catal. BEnviron. 145 (2014) 1-9.

[27] L.S. Ribeiro, J.J.M. Órfão, M.F.R. Pereira, Green Chem. 17 (2015) 2973-2980.

[28] M. Sankar, N. Dimitratos, P.J. Miedziak, P.P. Wells, C.J. Kiely, G.J. Hutchings, Chem. Soc. Rev. 41 (2012) 80998139.

[29] B.T. Kusema, L. Faba, N. Kumar, P. Mäki-Arvela, E. Díaz, S. Ordóñez, T. Salmi, D.Y. Murzin, Catal. Today 196 (2012) 26-33.

[30] L.S. Ribeiro, J.J.M. Órfão, M.F.R. Pereira, Green Process Synth. 4 (2015) 71-78.

[31] L.S. Ribeiro, J.J. Delgado, J.J.M. Órfão, M.F.R. Pereira, Catal. Today 279 (2017) 244-251.

[32] L.S. Ribeiro, J.J. Delgado, J.J.M. Órfão, M.F.R. Pereira, ChemCatChem 9 (2017) 888-896.

[33] L.S. Ribeiro, J.J. Delgado, J.J.M. Órfão, M.F.R. Pereira, Appl. Catal. B-Environ. 217 (2017) 265-274.

[34] L.S. Ribeiro, J.J.M. Órfão, M.F.R. Pereira, Green Process Synth. 6 (2017) 265-272.

[35] L.S. Ribeiro, J.J. Delgado, J.J.M. Orfão, M.F.R. Pereira, RSC Adv. 6 (2016) 95320-95327.

[36] L.S. Ribeiro, J.J.M. Órfão, M.F.R. Pereira, Bioresour. Technol. 244 (2017) 1173-1177.

[37] L.S. Ribeiro, J.J.M. Órfão, M.F.R. Pereira, Bioresour. Technol. 232 (2017) 152-158.
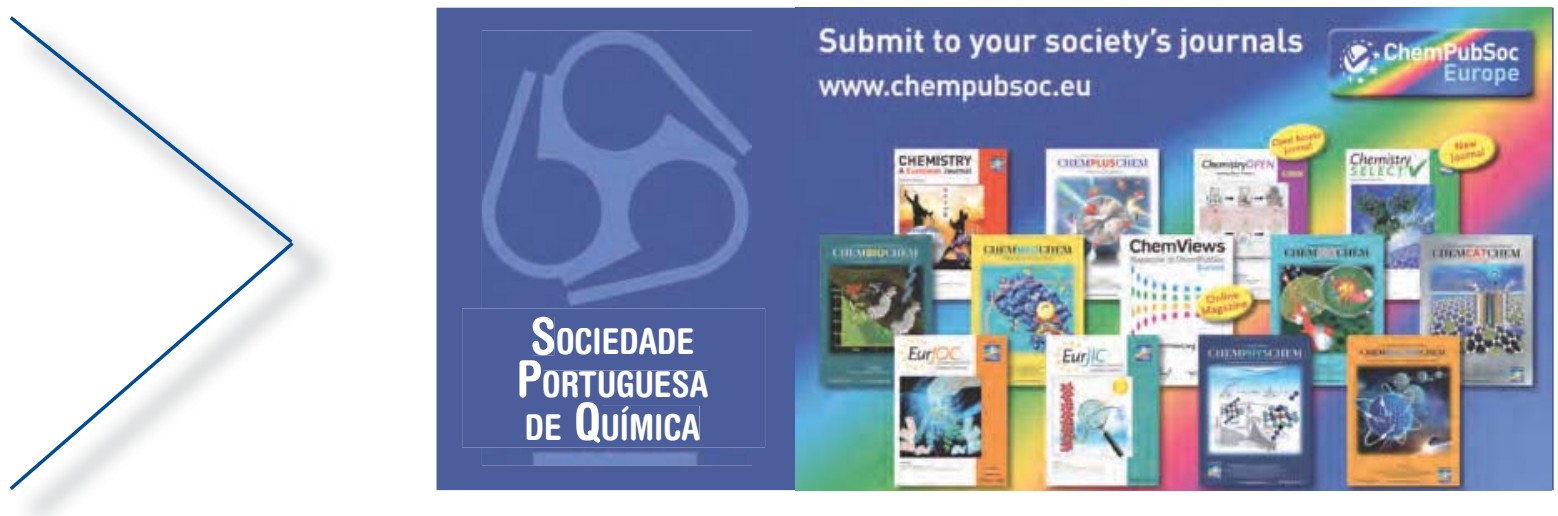